\title{
STRUCTURAL BEHAVIOR OF A TUBULAR WIND TOWER FOR A 1.5 MW TURBINE
}

\author{
FERNANDO E. TADAIESKI $^{1}$, JOÃO B. DE AGUIAR ${ }^{1}$,JOSÉ M. DE AGUIAR ${ }^{2}$
}

\author{
${ }^{1 .}$ Engenharia AeroEspacial, CECS, Universidade Federal do ABC \\ Av. dos Estados, 5001, Bangu, Santo André, SP, Brasil,CEP 09210-580 \\ fernando.tadaieskilufabc.edu.br, joao.aguiarlufabc.edu.br
}

\author{
${ }^{2 .}$ Ensino Geral, Faculdade de Tecnologia de São Paulo, FATEC-SP \\ Av. Tiradentes, 615 - Bom Retiro - São Paulo, SP, Brasil, CEP: 01124-060 \\ josemaguiaregmail.com
}

\begin{abstract}
Even though strong winds are not frequent in Brazil, many places, some along the costal shore, provide a potential to place eolic parks. In this work a tubular tower for a particular application is designed under some premises. In particular commercial sizes for sheet metal are chosen. Easy of transportation and assemblage are also considered. The dimensioned structure is then submitted to a static analysis using finite elements. Safety factors relative to inelastic behavior and instability are verified. Natural frequencies and the corresponding natural modes are also determined. Overall the structure is shown to satisfy functional requisites, but other evaluations are still pending.
\end{abstract}

Keywords— wind energy, tubular tower, dimensions, static analysis, natural frequencies, mode shapes

\section{Introduction}

Wind energy is object of research in many countries in an attempt to change the energy matrix with inclusion of clean energy. In this sense regions where strong winds occur in most of the year, are being populated by wind farms [WWEA, 2012]. In Brazil this is not a reality yet. Reason is that most of the energy comes from the use of hydraulic resources, still with some plants in construction. However, with fast increase in use of energy, and the depletion of available sites for new hydroelectric plants, this trend is taking place too. So far some installations are operating and many others are in construction [Mendes, T.F e Menezes, J.C., 2010]. They have an installed capacity with good year around effectiveness, around $30 \%$. But for some places larger capacity installations are devised. Applications involving use of several megawatt units, common in other parts, should be considered in the near future. Study of this kind of facility drove this research.

In the design process in most cases a site for a new installation is chosen [Atlas do Potencial Eólico Brasileiro, 2012], its potential evaluated, a turbine specified and a tower has to be designed. Prior to construction, the fixing base of the tower is also designed and constructed.

Depending on the size of the wind plant, a truss or tubular construction is chosen. Prices are different, but duration and rigidity vary a lot. Here a tubular concept is chosen. Prescribed a turbine, acceptable for the regime of winds in the installation site, loads are estimated. Usual dimensions for the base diameter, acceptable values of angles of cone and height are prescribed. Dimensioning starts then.

\section{Concept, Design and Analysis}

\subsection{Structural Concept}

Initial planning points toward a conical tower model with circular transversal cross section to suit construction, assemblage and functional purposes. The size parameters could be diameter $D_{0}$ at the base, cone angle $\alpha$ and height $H$ specified at the onset of the problem. The number of modules $m$ is also specified. Loading is also prescribed by choice of the turbine system and installation site. Boundary conditions consider tower rigidly fixed to the ground. The choices of tower material needs to take into account not only performance but also manufacturing restrictions. Dimensioning proceeds forward for the thickness at the root of the tower using a tubular beam model.

This kind of tubular construction has good rigidity and is preferred in most designs. In particular, manufacturing costs require use of sheet metal of standard dimensions. For reasons of transportation and assemblage at the installation site, modular construction is preferred.

Table1. Mechanical properties of structural steel

\begin{tabular}{|ll|}
\hline Property & Value \\
\hline Elastic modulus, E & $200 \mathrm{GPa}$ \\
Poisson's ratio, v & 0.30 \\
Yield strength, $S_{y}$ & $210 \mathrm{MPa}$ \\
Density, $\rho$ & $7850 . \mathrm{kg} / \mathrm{m}^{3}$ \\
\hline
\end{tabular}


Six modules, each one $10 \mathrm{~m}$ long are designed, and fitted with flanges fixed with bolts and nuts. Commercial thicknesses are employed in all modules.

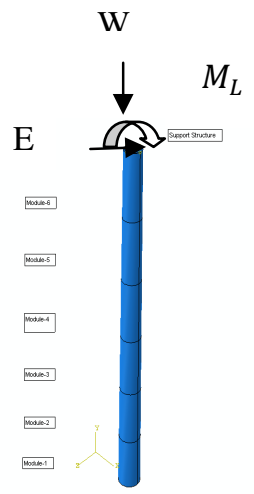

Figure 1Wind tower with 6 modules

\subsection{Preliminary Design}

In order to find the required thickness of the tower in every module, material, loading and boundary conditions have to be prescribed. The tower base is supposed completely fixed to the ground, whereas the top section is subjected to the loading provided by the turbine structure. Therefore this loading depends on the type of turbine used. It comprises a thrust load $E$, the weight component $W$ and the couple $M_{L}$. Furthermore there is the distributed lateral drag force $\lambda$, per unit length, caused by action of the wind on the tower. For a $1.5 \mathrm{MW}$ unit, Table 2 shows the main elements of specification. Rated wind speed is used in the design scenario.

Modeling the tower as a 2D, tubular beam structure leads to a first approximate value of the thickness required at the base of the tower, the critical section. Internal stress resultants at this section $<\mathrm{N}$, $\mathrm{S}, \mathrm{M}>$ are obtained considering the tower equilibrium equations, Figure 1:

$$
\begin{aligned}
& N=Y_{0} ; \quad Y_{0}=W \\
& S=X_{0} ; X_{0}=E+\int_{0}^{L} \lambda(x) d x \\
& M=M_{0} ; M_{0}=E L-M_{L}-\int_{0}^{L} \lambda(x) x d x
\end{aligned}
$$

Here $X_{0}, Y_{0}$ are the lateral and axial reactions at the root of the tower whereas $M_{0}$ is the encastre bending moment. Weight includes blades, transmission system, and generator, besides the structure own weight:

$$
W=W_{b}+W_{t}+W_{g}+W_{s}
$$

Power of the turbine $\mathrm{P}$ at rated velocity $v_{w}=12 \mathrm{~ms}^{-1}$ is related to the area swept by the blades $A_{b}=\pi R_{b}^{2}$, being $R_{b}$ the radius of the blades:

$$
P=\frac{\rho}{2} A_{b} v_{w}^{3} C_{p}
$$

where $C_{p}=4 a(1-a)^{2}$ is the power coefficient and $\rho$ is the mass density of the air, at the location and temperature of operation [Kulunk, 2011], usually close to $1.025 \mathrm{~kg} / \mathrm{m} 3$, whereas $a$ is the axial induction factor. Torque at the rotor axis may then be computed as:

$$
T=\frac{P}{v_{w}}
$$

From the power delivered by the installation, the thrust force $E$ may then be calculated as [Hansen,2008]:

$$
E=\frac{\rho}{2} A_{b} v_{w}^{2} C_{e}
$$

where coefficient $C_{e}$ is be defined as a function of power coefficient, $C_{e}=C_{p}(1+a)^{-1}$. The other loading term at the top of the tower $M_{L}=\sqrt{T^{2}+M_{b}^{2}}$ comes from the composition of torque and bending moment caused by the set of blades in balance. It depends on the arrangement of equipment in the top of the tower. A distance, external radius $R_{0}=D_{0} / 2$, from center line at the top of the tower is supposed here. Apart this, wind pressure, is expressed as:

$$
\lambda=\frac{\rho}{2} C_{d} v_{w}^{2} ; \quad v_{w}=\hat{v}_{w}(z)
$$

The stress components corresponding to the critical point in the section are:

$$
\begin{aligned}
& \sigma_{N}=\frac{N}{A} ; A=\frac{\pi}{4}\left(D_{0}^{2}-D_{i}^{2}\right) \\
& \sigma_{M}=\frac{M}{2 I} D_{0} ; I=\frac{\pi}{64}\left(D_{0}^{4}-D_{i}^{4}\right)
\end{aligned}
$$

being $D_{0}=D_{i}+2 t$.

These components can be added and solved for the thickness $t$ if the normal stress resultant is set to the value of the yield strength affected of a safety factor n:

$$
\sigma_{N}+\sigma_{M} \leq S_{y} / n
$$


Substituting the loading terms into this stress equation, leads to components of stress that are dependent on the arrangement of mechanical components, weight and wind parameters. This requires an iterative scheme of solution that asks for a root finding procedure of a fifth order polynomial equation:

$$
p(t)=a_{i} t^{i} ; i=1,2,3,4,5
$$

The resulting equation may be solved numerically using different techniques. Once determined the thickness at the tower base, weight of the tower is estimated, and from there a new value for the base thickness is computed. Then the thickness obtained is used for the first module, selecting a commercially available plate. The flanges in the bottom and top of the module are chosen to have the same constant thickness of the side shell.

Each module is fixed to the next module by means of a set of screws, designed separately. Once solved for the lower module, for there on, at every new higher position module, a new thickness is searched using stress resultants for the module. Adopted values come from commercially available sheet metal dimensions, Table 3.

Table 2. Main specifications of turbine

\begin{tabular}{|ll|}
\hline Variable & Value \\
Rated power, $P$ & $1.5 \mathrm{MW}$ \\
Rated wind speed, $V_{w}$ & $12 \mathrm{~ms}^{-1}$ \\
Wind speed range & $3.5 \leq V_{w} \leq 25$ \\
Rpm range of rotor & $12 \leq \omega_{r} \leq 20$ \\
Blade weight, $W_{b}$ & $44.5 \mathrm{kN}$ \\
Turbine weight, $W_{t}$ & $30 . \mathrm{kN}$ \\
Blade radius, $R_{b}$ & $35.25 \mathrm{~m}$ \\
Generator weight, $W g$ & $50 \mathrm{kN}$ \\
\hline
\end{tabular}

\subsection{Static Analysis}

Once a set of thicknesses is chosen to the modules $j=1,2 \ldots, 6$ of the tower, the whole structure is analyzed using finite elements [Abaqus, 2009]. Each module is discretized with shell elements, with internal load transfer among modules produced by connectors, in this case, bolted connections as well as contact.

Between undeformed and deformed configurations, the virtual work of the internal resultants $\delta U$ and external tractions $\delta W$ are equal. The internal resultants comprise three parts, membrane, bending and shear contributions [Zienkiewicz, 0. and al, ]:

$$
\delta U=\sum_{j=1}^{6}\left[\delta U_{j}^{m}+\delta U_{j}^{b}+\delta U_{j}^{s}\right]
$$

The work of the membrane resultants $\mathbf{n}^{T}=\left\lfloor\begin{array}{lll}n_{l} & n_{\theta} & n_{l \theta}\end{array}\right\rfloor$ over the associated virtual deformations $\delta \boldsymbol{\varepsilon}$ for module $\mathrm{j}$, with thickness $t_{j}$, is:

$$
\delta U_{j}{ }^{m}=\int_{A_{j}} \mathbf{n}^{T} \delta \boldsymbol{\varepsilon} d A
$$

The virtual work associated with the bending resultants $\mathbf{m}^{T}=\left\lfloor\begin{array}{lll}m_{l} & m_{\theta} & m_{l \theta}\end{array}\right\rfloor$ over the corresponding virtual curvatures $\delta \boldsymbol{\kappa}$ writes as:

$$
\delta U_{j}{ }^{b}=\int_{A_{j}} \mathbf{m}^{T} \delta \mathbf{k} d A
$$

Finally the shear virtual work computed from the shear resultants $\mathbf{S}^{T}=\left\lfloor\begin{array}{ll}q_{l} & q_{\theta}\end{array}\right\rfloor$ over the associated shear deformations $\delta y$ is:

$$
\delta U_{j}{ }^{b}=\int_{A_{j}} \mathbf{q}^{T} \delta \gamma d A
$$

The external virtual work comprises the component relative to the line load $\lambda$, arising from the external wind pressure over the external tower surface, plus the contribution from contact pairs and the point loading where the machinery is located. The virtual work totals:

$$
\delta W=\int_{L} \lambda \delta w d l+\sum_{j} \int_{C_{j}} \lambda_{c} \delta \mathbf{d}_{c} d A_{c}+\delta W
$$

Each of the entrances in the preceding equations may be related to the associated deformation variable by means of constitutive equations, if membranebending coupling is ignored:

$$
\begin{aligned}
& \mathbf{n}=\mathbf{C}_{n} \boldsymbol{\varepsilon} \\
& \mathbf{m}=\mathbf{C}_{m} \boldsymbol{\kappa} \\
& \mathbf{s}=\mathbf{C}_{s} \boldsymbol{\gamma}
\end{aligned}
$$

Discretization of the structure by quadrilateral shell elements requires interpolation functions $N_{N}$ for the displacement field $d=\left[\begin{array}{lll}u_{l} & u_{\Theta} & w\end{array}\right\rfloor$ with particular forms for the internal resultants:

$$
\boldsymbol{\varepsilon}=B_{n} \mathbf{d}^{N} ; \quad \boldsymbol{\kappa}=B_{k} \mathbf{d}^{N} ; \quad \boldsymbol{\gamma}=B_{\gamma} \mathbf{d}^{N}
$$

Introduction of these interpolation functions allows the computation of strains, curvatures and shear deformations in terms of nodal displacements. Equilibrium may be cast in the form:

$$
\mathbf{K} \boldsymbol{d}^{N}=\boldsymbol{F}
$$


Where the stiffness matrix $\mathbf{K}=K_{m}+K_{b}+K_{s}$ comprises the partition associated with the normal, bending and shear components. The force vector contains lateral and point contributions at the top of tower where the machinery is placed, $F_{\lambda}+F$. [Belytschko et al, 2000].

Table 3. Main Dimensions of the wind tower

\begin{tabular}{|l|l|l|l|l|}
\hline Module & $\begin{array}{l}\text { Base } \\
\text { Radius }\end{array}$ & $\begin{array}{l}\text { Plating } \\
\text { Thickness }\end{array}$ & $\begin{array}{l}\text { Height } \\
\mathrm{m}\end{array}$ & $\begin{array}{l}\text { Weight } \\
\mathrm{kN}\end{array}$ \\
\hline 1 & 2.00 & 15 & 10 & 150.1 \\
\hline 2 & 1.91 & 14 & 10 & 133.9 \\
\hline 3 & 1.83 & 13 & 10 & 119.0 \\
\hline 4 & 1.75 & 12 & 10 & 104.6 \\
\hline 5 & 1.66 & 11 & 10 & 91.1 \\
\hline 6 & 1.58 & 10 & 10 & 78.6 \\
\hline
\end{tabular}

Response of the structure to the design loading is analyzed with finite elements. Discretization is overall uniform, with densification at the transition points from one module to the other, and along top sections where machinery is fixed. Same shell element is used overall. Plot of the displacement field of the complete assemblage, containing 6 modules, is shown in Figure 2. As it would be expected, most of the displacement is present at the top of the tower, with lateral, bending caused displacements predominant.

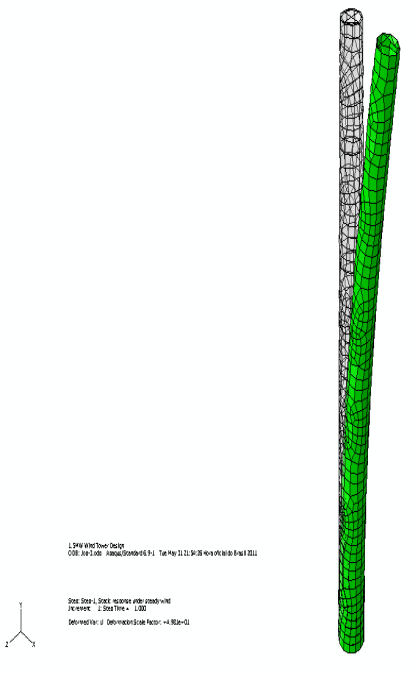

Figure 2 Static displacement field of the tower

Equivalent stresses, on the other hand, as measured by Von Mises stress are present in Figure 3. They show a comfortable distance from the yield resistance in most of the regions. Critical points appear at the basis of the tower. Points in the top of the tower show large stress concentrations that have to be addressed in the construction part of the project. They have to do with the design of the support of the mechanical components. For conditions reflecting special loading events, with winds, with larger return period than that supposed in Table 2, much larger stress values will appear, with bending prevalence, should be expected, with inelastic deformations present [Crisfield,M.A.,1991]]

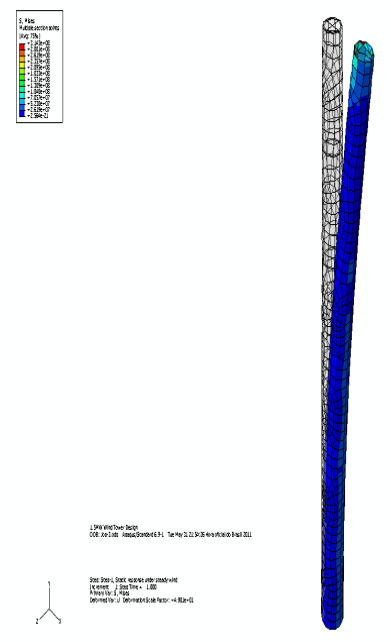

Figure3. Mises stress distribution over the tower

\section{Dynamic Response}

\subsection{Natural Frequencies}

In order to understand the dynamic behavior of the wind tower inertia forces must be introduced. Under unsteady winds, the tower will oscillate back and forth around a position that may be the undeformed or the deformed one. This movement will depend on the rigidity of the tower itself. For the harmonic response, without damping, equilibrium equation now read as [7]:

$$
\mathbf{M} \ddot{\mathbf{d}}^{N}+\mathbf{K} \mathbf{d}^{N}=\mathbf{0}
$$

where $\mathbf{M}$ is the mass matrix of the assemblage of 6 modules, with $N_{N}$ discretizing the mass:

$$
\mathbf{M}=\sum_{i} \int_{A_{i}} \mathbf{N}_{N}^{T} \rho \mathbf{N}_{N} t_{i} d A
$$

\subsection{Mode Shapes}

Whenever harmonic motion may be considered, accelerations may be written in terms of amplitudes and frequencies, so that Eq. (19) may be replaced by [Zienckiewecz et al, 2005]:

$$
\left[\mathbf{K}-\omega^{2} \mathbf{M}\right] \mathbf{d}^{N}=0
$$

That may be solved for the eigenvalues that make the above product null for matrix $\mathbf{K}-\omega^{2} \mathbf{M}$ and vector $\mathbf{d}^{N}$ not null. This occurs at specified values of eigenfrequencies $\omega_{j}$ with corresponding eigenvec- 
tors $d_{j}$. Problem as discretized for the static analysis is submitted to a search for characteristic values in a disturbance analysis.

Results are presented in Figures 4 up to Figure 8, for the first five modes. First four modes are bending modes, whereas fifth one is a shell membrane coupled to a bending mode. Corresponding natural frequencies of the structure appear in Table 5.

In general first modes convey most of the energy in the spectrum, and are more important. Here they have been drawn from an undeformed initial reference. Result from the disturbances around a deformed configuration, after some persistent wind, would give different results. Another point to remind is that the response would be constructed from this perturbation analysis only for linear deflections from undisturbed conditions.

Table 5 Natural frequencies of the tower

\begin{tabular}{|ll|} 
Mode number & Frequency,rps \\
\hline 1 & 1.4558 \\
2 & 1.4560 \\
3 & 6.5112 \\
4 & 6.5132 \\
5 & 8.6619 \\
\hline
\end{tabular}

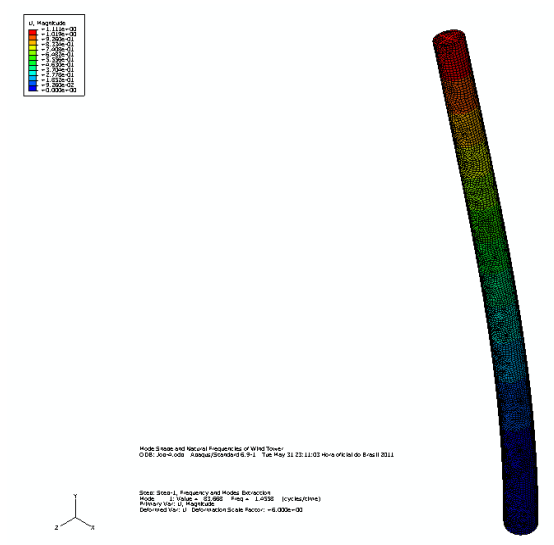

Figure4. First mode shape of tower
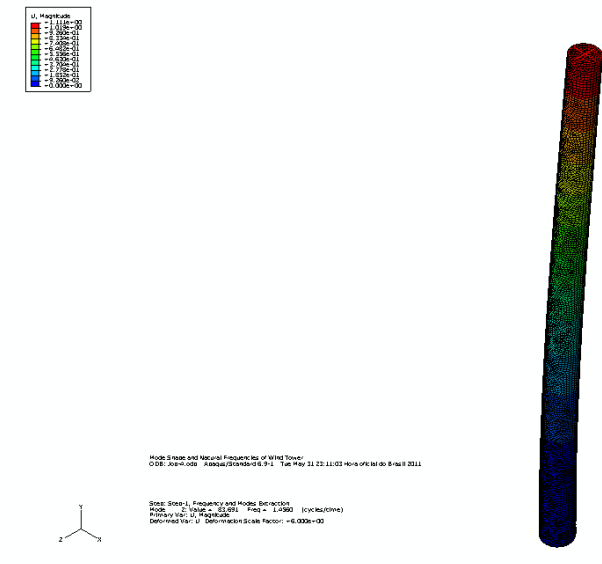

Figure 5 Second mode shape of wind tower
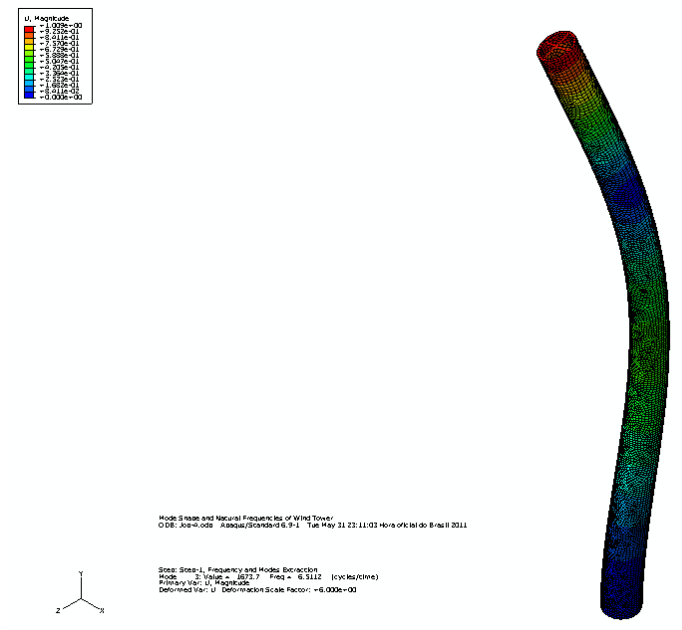

Figure 6 Third mode shape of wind tower
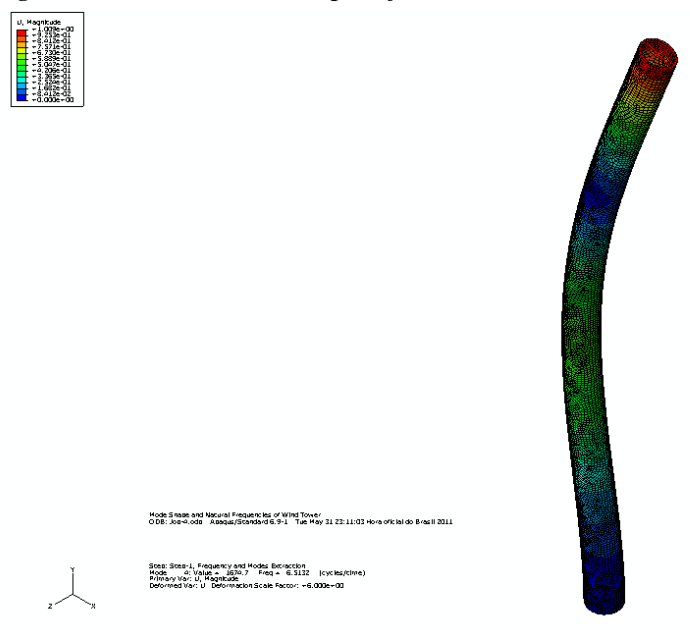

Figure 7 Fourth mode shape of wind tower 


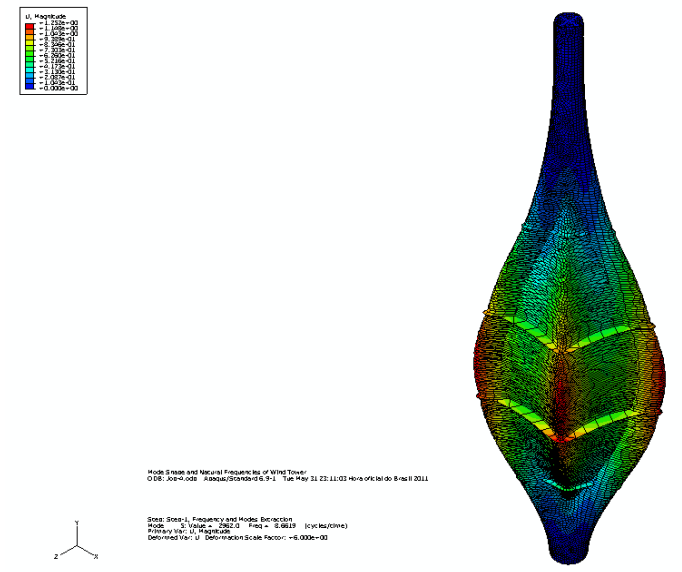

Figure 8 Fifth mode shape of wind tower

\section{Conclusions}

Even though in a preliminary phase, it is clear that the concept has passed major initial checks. However some setbacks may appear when fatigue verification is done. Instability analysis for the diverse buckling modes was not done, but it is foreseen as improbable. The range of frequencies of rotor excitation is in the interval $0.2 \leq \omega_{r} \leq 0.0348 \mathrm{rps}$ (Table 2), whereas the lowest frequency of the tower is $1.4558 \mathrm{rps}$ (Table 5 ). Therefore resonance is avoided. Concerning three the blades, they also introduce excitation at frequencies three times the rotating frequency, therefore in the interval $0.6 \leq w_{b} \leq 0.1044 \mathrm{rps}$. Again the structure is not in a critical situation. Response for these cases must, however, be sought. [UIowaWiki, 2013]

Some points need to be addressed in the research:

i. Find the best material for construction of the tower; Weight of the tower is acceptable, but some items have not been taken into account yet;

ii. Detail the structural design, verifying the interaction between modules, with special care to the mechanisms of shear and bending transfer;

iii. Do verification of critical scenarios, with winds of up to 50 years return period;

Finally, location of the wind tower is another issue to deal with. In the state of São Paulo there are several areas of dense population that require, at least when demand reaches peaks, additional power supply. That extra power could come from wind farms. This sort of size of wind installation may fit well that quest.

\section{References}

^ "World Wind Energy Association". Retrieved 31

October 2012.
Atlas do Potencial Eólico Brasileiro (2012), Cresesb-

Cepel, Rio de Janeiro, RJ

Mendes, T. F. and Menezes, J. C. (2010). Estudo da Sensibilidade e Dimensionamento Estrutural de Torres Tubulares para geradores Eólicos. VI CONEM, Congresso Nacional de Engenharia Mecânica, Campina Grande, Pa, Brasil

Kulunk, E. (2011),“Aerodynamics of Wind Turbines", in Fundamental and Advanced Topics in Wind Power, Editor Rupp Carriveau, InTech DOI: $10.5772 / 17854$

Zienkiewiecz, O. and Taylor, R.C., Zhu, (2005). The Finite Element Method: Its Basis and Fundamentals, $6^{\text {th }}$ edition, McGraw-Hill

Crisfield, M.A., (1991), “Non-Linear Finite Element Analysis of Solids and Structures", vol.1, $1^{\text {st }}$. ed., John Wiley \& Sons,

Hansen, M., (2008) “ Aerodynamics of Wind Turbines", $2^{\text {nd }}$. Ed., Earthscan,

Belytschko,T., Liu, W.K. and Moran.B., (2000), "nonlinear Finite Elements for Continua and Structures", John Wiley and Sons, Ltd. England

Abaqus, 2009 , “A Finite Element Analysis Program”, Dassault Systèmes, France

UIowa,Wiki, 2013

https://wiki.uiowa.edu/display/greenergy/Wind 